\title{
Applying a Political Economy of Health standpoint to traditional food acquisition practices and the inequitable prevalence of obesity and diabetes amongst First Nations peoples in British Columbia
}

\author{
Colin Merz and Malcolm Steinberg \\ Simon Fraser University, Burnaby, BC, Canada
}

\begin{abstract}
The inequitable population prevalence rates of obesity and diabetes being experienced by First Nations peoples in British Columbia require public health protection practitioners to deepen their inquiry into the social determinants of these chronic conditions. These attempts need to be placed within the context of food insecurity that is garnering growing attention from public health at large and, more specifically, within the emerging Indigenous consensus understanding of the relationship between the ongoing nutrition transition and the inequitable prevalence rates of these conditions. We suggest that these reflections are productively theorized from a Political Economy of Health standpoint and supported by representative findings from the First Nations Regional Longitudinal Health Survey. This theoretical perspective supports the viewpoint that the inequitable expression of these chronic conditions can be attributed to the nutrition transition that populations experienced as they were shifted from a traditional subsistence diet to a commoditized, industrialized food production system. This analysis also supports the structural recommendations of the British Columbia Food Systems Network Working Group on Indigenous Food Sovereignty that would remove barriers and threats to traditional food acquisition. These include making environmental protection and conservation of biological diversity a priority in all land use planning; setting aside adequate tracts of land for the protection, conservation, and restoration of Indigenous food systems; giving priority to traditional food and cultural values in contemporary forestry, fisheries, rangeland, and agrarian management policies and practice; and giving priority to Indigenous food and cultural harvesting over commoditized, export-oriented commercial harvesting. Public health protection practitioners will be progressively challenged to support these recommendations by the communities they serve. Although there is no guarantee that implementation of these recommendations will reverse the trend of decreasing participation rates in traditional food harvesting in British Columbia, we suggest that unless many of the systemic irrationalities, vested interests, and historically unjust rationales for maintaining the status quo with respect to Indigenous food sovereignty are interrogated and challenged, an ancient lifeway grounded in demonstrably sustainable traditional food harvesting practices will remain threatened.
\end{abstract}

Key words: Indigenous food sovereignty, social determinants of health, public health protection, eco-social sustainability.

\section{Introduction}

This article invites public health protection practitioners to critically consider how evidence-informed policy and field-level decision making is contextually informed and situated (Berger and Luckmann 1966; Bryant et al. 2010; Hankivsky 2011) and to further consider how historically sedimented actions and understandings can become socially and physiologically pathological as "mutually shaping contexts" (Lincoln and Guba 1985) change over time. Contested land issues are a case in point. As anthropologist Paul Nadasdy (2003) argues:

Corresponding author: Colin Merz (email: camerz@sfu.ca)
A growing number of terms critical to ongoing land claims negotiations, wildlife management debates, and environmental conflicts in northwestern Canada - terms like "land", "hunting", "resources", and "property" that may initially seem straightforwardare actually fundamentally contested. All parties may agree on their importance, yet negotiating parties may mean very different things when they use the same terms. Participants predictably take their own meanings to represent "common sense", but the more powerful parties regularly build their meanings into legal agreements (Cruikshank 2005).

If practitioners inadvertently fail to be as "reflexive" (Bourdieu 1992) as the job requires and do not investigate the unarticulated premises of policies, the social legitimacy of statutes that they have the duty to implement and enforce, or become ensnared in the daily churn of a technical-rational 
algorithmic approach to health protection practice, then to some extent these practitioners are relinquishing their professionalism and potential efficacy. Public health protection is dependent upon its diverse practitioners courageously integrating all of their different ways of knowing and being in the world. This requires determining when and how to blur and hybridize different types of action and understanding, quantitative and qualitative, to protect from colonization what Canadian sociologist Dorothy Smith (2006) calls our "everyday lives" and Frankfurt School philosopher Jürgen Habermas (1984) refers to as our "Lebenswelt" (lifeworlds).

In this article we propose that the emerging Indigenous consensus understanding (BCFSN 2008; PFPIC 2011) of the relationship between the ongoing "nutrition transition" (Popkin 1993) and the inequitable population prevalences of obesity and diabetes being experienced by First Nations peoples in British Columbia (BC) (Reading 2010) is productively theorized from a "Political Economy of Health" standpoint. By applying such a sociologically and philosophically informed perspective, new ways of thinking about and potentially mitigating and correcting this public health inequity become knowable and actionable. This article also serves to deepen the food insecurity discourse that is garnering growing attention by public health agencies.

\section{Discussion}

Two well-documented health inequalities between British Columbian First Nations and non-First Nations populations are the prevalence rates of obesity and diabetes. From the BC Provincial Health Officer's (2009) annual report Pathways to Health and Healing, the adult self-reported obesity and diabetes prevalence are shown in Table 1.

These BC-specific data are consistent with population prevalence inequalities reported at the aggregated national level by various health surveys (PHAC 2014), albeit with prevalence markedly lower in $\mathrm{BC}$ compared with national levels for both populations (Table 2).

Table 1. Comparison of obesity and diabetes prevalence in British Columbia.

\begin{tabular}{|l|c|c|}
\hline & $\begin{array}{l}\text { First Nations } \\
(\mathbf{\%})\end{array}$ & $\begin{array}{l}\text { Non-First } \\
\text { Nations (\%) }\end{array}$ \\
\hline Obesity (BMI of >30) & 22.6 & 12.9 \\
\hline Diabetes & 6.7 & 4.8 \\
\hline
\end{tabular}

Table 2. Comparison of obesity and diabetes prevalence in Canada.

\begin{tabular}{|l|c|c|c|}
\hline & $\begin{array}{l}\text { First } \\
\text { Nations on } \\
\text { reserve (\%) }\end{array}$ & $\begin{array}{l}\text { First } \\
\text { Nations off } \\
\text { reserve (\%) }\end{array}$ & $\begin{array}{l}\text { Non-First } \\
\text { Nations } \\
\text { (\%) }\end{array}$ \\
\hline $\begin{array}{l}\text { Obesity (BMI }> \\
30)\end{array}$ & 34.8 & 28.4 & 17.9 \\
\hline Diabetes & 17.2 & 10.3 & 5.0 \\
\hline
\end{tabular}

It should be noted that in the Canadian context, the collection of health status data for First Nations populations has been contested and problematic, with the major national health surveys (e.g., National Population Health Survey, Canadian Community Heath Survey, Canadian Health Measures Survey) excluding, or being excluded by, the on-reserve populations. The Aboriginal Peoples Survey is also restricted to the off-reserve population. To redress this gap in health status data collection for on-reserve populations, in 1997 the First Nations Regional Health Survey (RHS) was initiated by the First Nation Indigenous Governance Centre with data collection occurring in seven regions of the country. Building on the success of this first cross-sectional survey, the RHS was expanded to all regions of the country and the survey design was changed from cross-sectional to longitudinal, with data collection occurring at four-year intervals. Although the First Nations Regional Longitudinal Health Survey is funded primarily through Health Canada's First Nations and Inuit Health Branch, the survey is predicated on the OCAP principles of First Nations Ownership, Control, Access, and Possession (FNIGC 2014). OCAP is one of several sets of ethical guidelines and recommendations that have emerged to assist researchers and practitioners proposing to conduct research and collect information with First Nations peoples, others include the Assembly of First Nations' Ethics in First Nations research, the Tri-council Policy Statement's Research involving the First Nations, Inuit, and Métis Peoples of Canada, and the University of Victoria's Protocols and principles for conducting research in an Indigenous context. The decolonizing potential of the RHS is explicitly identified in the RHS Cultural Framework:

Research should be presented back to communities in ways that are usable and reinforce their ways of seeing, relating, knowing and being. Simply stated, the RHS Cultural Framework encompasses the total health of the total person within the total environment (Dumont 2005).

As the only national research initiative under complete First Nations control, "the RHS has given new meaning to First Nations self-determination in research and provided the research community with a demonstration of how the principles of OCAP can be successfully implemented" (FNIGC 2012). Phase 1 (2002-2003) and Phase 2 (2008-2010) have been completed and for the first time there is a culturally appropriate, methodologically rigorous dataset available to analyze longitudinal trends in the prevalence of on-reserve health conditions such as diabetes and obesity. These Canadian First Nations specific data are congruent with observations from the Canadian studies that excluded on-reserve populations and confirm that Indigenous populations are experiencing an epidemic of nutrition and physical activity related illnesses (Young et al. 2000; Fee 2006). Discussion of these First Nations specific data argue that the historically observed (Neel 1962) and contemporary increasing prevalences of obesity and diabetes amongst Indigenous populations is frequently attributed to the nutrition transition experienced as populations are shifted from a traditional subsistence diet to a commoditized, industrialized food production system. 
Although not the focus of this article, descriptions of the micro-proximal biologic causal relationships between decreased First Nations participation in traditional food acquisition activities and obesity and diabetes is well developed in the biomedical literature, with its research foci including the nutritional characteristics of traditional versus market foods, energy expenditures associated with traditional food acquisition activities, and the genomic characterization of metabolic pathways in First Nations populations. Much of this "biomedically informed research" (Illich 1976; Klinenberg 2003; Dew 2012) has historically focused on some variation of the thrifty genotype-phenotype hypothesis which, as argued by Fee (2006) and others, has proven unproductive and may in fact be perpetuating the colonial discourse and exacerbating the health inequity (Battiste 2000; Meyer and Avarado 2010). The undeniable value of the biomedical research program lies in its secondary and tertiary prevention strategies of improved diagnosis and treatment of affected individuals, but from a primary and primordial (Porta and Last 2008) prevention orientation, it has little to offer and should not be hegemonic in public health protection practice (Kalitzkus and Twohig 2009; De Maio 2010). The Political Economy of Health standpoint facilitates the theorizing of practical upstream interventions to potentially mitigate this inequitable burden of illness between First Nations and non-First Nations British Columbians.

\section{Challenges}

As discussed previously, there is a disproportionate prevalence of obesity and diabetes documented in Indigenous populations in $\mathrm{BC}$ when compared with non-Indigenous populations cooccupying this geographical region. The remainder of this article will utilize a Political Economy of Health theoretical standpoint for understanding how this health inequality has developed and for illustrating why this health inequality is in fact a socially determined health inequity. For the purpose of this article, a Political Economy of Health standpoint is defined as:

Focusing on the social structures and institutions that create, enforce, and perpetuate poverty and privilege... that take a critical, historical approach to analyzing the social production, distribution, and treatment of health and disease... that focus on the social determinants of disease etiology and health inequality rather than on individualistic, biomedical, geographical, cultural, or psychological explanations of ill health (Restivo 2005)

Recognizing that historical circumstances are unique to each local geographic region and that the structures and processes operating in each locale will differ, the remainder of this article will apply this standpoint to the nutrition transition as it is being experienced by First Nations peoples in BC.

Most of BC remains unceaded First Nations territory. Prior to 2000, with the Nisga'a Final Agreement, the only historic treaties signed between sovereign First Nations and representatives of colonizing nations were the Douglas Treaties (1850-1854) on southern Vancouver Island and Treaty 8 (1899) that included a region of northeastern BC. (AANDC 2014).
Yet, despite the absence of a legal right of occupation, the settler population of BC continued to grow with proportionately large population influxes occurring during the various unsustainable resource exploitation booms (e.g., the fur trade of the early to mid-1800s, the Fraser Canyon and Cariboo gold rushes in the 1850s and 1860s, export oriented lumber mills starting in the 1860 s, the steamship driven expansion of coal mining around Nanaimo in the 1880s, and the salmon canneries of the late 1800s and early 1900s) (Barman 2007). With the completion of the transcontinental railroad in 1885 , the Indigenous population of $\mathrm{BC}$ had been reduced from an estimated precontact population of 250000 to approximately 28000 and would reach its nadir of 23000 in 1929 (Muckle 2007). Remarkably, at this First Nations population low point, the proportion of the total provincial population that was First Nations was approximately $4 \%$, which is what the proportion is today.

The most significant direct result of this combination of First Nations population collapse and settler population expansion was the segregation of traditionally mobile First Nations populations (i.e., geographically distinct areas of occupation depending on seasonal availability of resources) to single reserves, often in marginalized locations. This segregation of First Nations individuals and communities to reserves was accomplished via a statutory instrument, the federal Indian Act of 1876. At the time of enactment, First Nations individuals were granted the "right" to access subsistence resources such as fish, game, and botanicals; yet, because of the increasing settler populations and the free-market commoditization of the productive capacity of the ecosystems, the right of First Nations to practice in their traditional subsistence lifeways was often a cruel legal fiction (Brody 1981; Alfred 2009; Gill 2009; Irlbacher-Fox 2009; Cote 2010). The grasslands of the interior plateau were converted to rangeland for cattle and sheep; salmon stocks on some of the most productive river systems on the continent were decimated, packed into tin cans and shipped across the globe to feed the commonwealth empire. Steller's Sea Cow on the north coast and Dawson's Caribou on Haida Gwaii were hunted to extinction; local populations of Blue, Sei, and Right Whales and the Sea Otter were extirpated (BCMELP 2014). The fertile river valleys were put to the plow and the settler communities mushroomed at the ports, lakes, and river confluences. Ecosystems that had sustained Indigenous populations for thousands of years, since "time immemorial", were obliterated, clear-cut into wastelands and entire valleys and their associated cultural sites were flooded for massive hydroelectric megaprojects. The cumulative effect of 150 years of industrial scale settler development in BC was the impoverishment, marginalization, and undermining of the health of First Nations peoples (Elsey 2013). Reassuringly, despite this extensive environmental degradation and contamination, the inherent resiliency of the natural ecosystems remains, as confirmed by the recent findings the First Nations Food, Nutrition, and Environment Study (Chan et al. 2011) that found that the levels of contaminants in a comprehensive sampling of traditional foods in BC are generally below toxicological levels of concern. 


\section{Future directions}

The tangible elements of the Political Economy of Health standpoint outlined above are:

- the illegal occupation of the land base by colonial administrations and the settler populations they encouraged;

- the enactment and enforcement of legal statues of segregation; and

- the free-market commoditization and unsustainable exploitation of the natural resources and ecosystems the First Nations peoples depended upon.

Applying a Political Economy of Health standpoint does not explicitly identify the micro-proximal causal factors of the inequitable prevalence of obesity and diabetes, rather this standpoint is useful for identifying where health inequities researchers should focus their attention to identify potential macro-proximal health determinants. We hypothesize from this standpoint that an overarching Indigenous social determinant of health, explicitly the historical and extant structures and institutions of colonialism, may be manifesting its detrimental health affects through the embodied physical activity of traditional food acquisition. Traditional food acquisition activities include fishing, harvesting-gathering, and hunting and trapping. It is our assertion that the decreasing First Nations participation rates in traditional food acquisition activities may be a contributing proximate cause of the disparate prevalences in obesity and diabetes. Comparing data from RHS 2008-2010 with RHS 2002-2003, a significant absolute and a large relative decline in the proportion of First Nations adults participating in traditional food acquisition activities has been documented over only an eight-year period (Table 3).

Recognizing that the etiology of obesity and diabetes is complex and onset is typically insidious, occurring progressively over decades, and that these conditions are often present in the same individual as co-morbidities, there does appear to be an inverse correlation between traditional food acquisition participation rates and prevalence of obesity and diabetes observed in the First Nations population.

Recognizing that public health protection practice, or better "praxis", in the social epidemiology tradition should be action oriented (Kemmis et al. 2014), we conclude this article by building on earlier Indigenous community-generated recommendations, relying on the work of the British Columbia Food Systems Network Working Group on Indigenous Food Sovereignty. Acknowledging that the hypothesized inverse relationship between prevalence of obesity and diabetes in First Nations peoples and traditional food acquisition participation rates is tentative, this lack of "scientific certainty" (Feyerabend 1993) must not be a barrier to taking steps to reverse the observed dramatic decreases in participation rates. Consistent with the Political Economy of Health standpoint, structural recommendations from the Working Group's Final Report (BCFSN 2008) that would remove barriers and threats to traditional food acquisition include:

- making environmental protection and conservation of biological diversity a priority in all land use planning;

- setting aside adequate tracts of land for the protection, conservation, and restoration of Indigenous food systems;

- giving priority to traditional food and cultural values in contemporary forestry, fisheries, rangeland, and agrarian management policies and practice; and

- giving priority to Indigenous food and cultural harvesting over commoditized, export-oriented commercial harvesting.

Implementation of these recommendations by the various policy sectors enacting legitimate consensual authority (Habermas 1989; Sennett 2012), guided by public health protection practitioners, will have innumerable "eco-social" co-benefits (Knudtson and Suzuki 1992; Krieger 2011; Worthy 2013) in addition to potentially mitigating the inequitable prevalence of obesity and diabetes between First Nations and non-First Nations peoples in BC.

Returning to this article's beginning, clearly these recommendations are politically charged and epistemologically situated and there is no guarantee (Cajete 2000) that their implementation will reverse the trend of decreasing participation rates in traditional food harvesting in BC. Yet, unless many of the systemic irrationalities, vested interests, and historically unjust rationales for maintaining the status quo (Warry 2007; Smith 2012) with respect to Indigenous food sovereignty are interrogated and challenged, an ancient lifeway grounded in demonstrably sustainable traditional food harvesting practices will remain threatened.

Table 3. First Nation traditional food harvesting participation rates in Canada.

\begin{tabular}{|l|c|c|c|}
\hline Activity & $\begin{array}{l}\text { RHS 2002-2003 } \\
\text { participation rate (\%) }\end{array}$ & $\begin{array}{l}\text { RHS 2008-2010 } \\
\text { participation rate (\%) }\end{array}$ & $\begin{array}{l}\text { Relative } \\
\text { decrease (\%) }\end{array}$ \\
\hline Fishing & 42.8 & 32.2 & 25 \\
\hline Berry picking or other food gathering & 38.1 & 28.3 & 26 \\
\hline Hunting or trapping & 31.9 & 22.1 & 31 \\
\hline
\end{tabular}

RHS, Regional Health Survey. 


\section{References}

AANDC (Aboriginal Affairs and Northern Development Canada). 2014. Fact Sheet: British Columbia Treaty Negotiations. [Online] Available at: http://www.aadnc-aandc.gc.ca/eng/1100100016299/ 1100100016300. [Accessed 9 July 2014].

Alfred, T. 2009. Peace, Power, Righteousness: An Indigenous Manifesto (2nd Ed.). Oxford University Press: Don Mills.

Assembly of First Nations. 2009. Ethics in First Nations research. [Online] Available at: http://www.afn.ca/uploads/files/rp-research_ ethics_final.pdf. [Accessed 9 July 2014].

Barman, J. 2007. The West Beyond the West: A History of British Columbia. University of Toronto Press: Toronto.

Battiste, M. (Ed.). 2000. Reclaiming Indigenous Voice and Vision. UBC Press: Vancouver.

Berger, P., and Luckmann, T. 1966. The Social Construction of Reality: A Treatise in the Sociology of Knowledge. Anchor: New York.

BCFSN (British Columbia Food Systems Network). 2008. Working group on indigenous food sovereignty - Final activity report. [Online] Available at: http://foodsecurecanada.org/sites/foodsecure canada.org/files/WGIFS\%20Final\%20Report\%202\%20March.\%2008. pdf. [Accessed 9 July 2014].

BCMELP (British Columbia Ministry of Environment, Lands and Parks). 2014. Extinct and extirpated species. [Online] Available at: http://www.env.gov.bc.ca/wld/documents/extinct.pdf. [Accessed 9 July 2014].

British Columbia Provincial Health Officer. 2009. Pathways to Health and Healing - 2nd Report on the Health and Well-being of Aboriginal People in British Columbia. Provincial Health Officer's Annual Report 2007. Ministry of Healthy Living and Sport: Victoria.

Bryant, T., Raphael, D., and Rioux, M. (Eds.). 2010. Staying Alive: Critical Perspectives on Health, Illness and Health Care (2nd Ed.). Canadian Scholars' Press Inc: Toronto.

Cajete, G. 2000. Native Science: Natural Laws of Interdependence. Clear Light Publishers: Santa Fe.

Canadian Institutes of Health Research, Natural Sciences and Engineering Research Council of Canada, and Social Science and Humanities Research Council of Canada. 2010. Tri-council policy statement: Ethical conduct for research involving humans: Research involving the First Nations, Inuit and Métis Peoples of Canada. [Online] Available at: http://www.pre.ethics.gc.ca/eng/ policy-politique/initiatives/tcps2-eptc2/chapter9-chapitre9/. [Accessed 9 July 2014].

Chan, L., Receveur, O., Sharp, D., Schwartz, H., Ing, A., and Tikhonov, C. 2011. First Nations Food, Nutrition and Environment Study (FNFNES): Results from British Columbia (2008/2009). University of Northern British Columbia: Prince George.

Cote, C. 2010. Spirits of Our Whaling Ancestors: Revitalizing Makah and Nuu-chah-nulth Traditions. University of Washington Press: Seattle.

Cruikshank, J. 2005. Do Glaciers Listen? Local Knowledge, Colonial Encounters and Social Imagination. UBC Press: Vancouver.

De Maio, F. 2010. Health and Social Theory. Palgrave Macmillan: New York.

Dew, K. 2012. The Cult and Science of Public Health. Berghahn Books: New York.
Dumont, J. 2005. First Nations Regional Longitudinal Health Survey (RHS) Cultural Framework. [Online] Available at: http://fnigc.ca/ sites/default/files/ENpdf/RHS_General/developing-a-cultural-frame work.pdf. [Accessed 9 July 2014].

Elsey, C. 2013. The Poetics of Land and Identity among British Columbia Indigenous Peoples. Fernwood Publishing: Winnipeg.

Fee, M. 2006. Racializing narratives: obesity, diabetes and the 'aboriginal' thrifty genotype. Social Science and Medicine, 62(12): 2988-97. doi: 10.1016/j.socscimed.2005.11.062.

Feyerabend, P. 1993. Against Method (3rd Ed.). Verso: London.

FNIGC (First Nations Information Governance Centre). 2012. First Nations Regional Health Survey (RHS) 2008/10: National Report on Adults, Youth and Children Living in First Nations Communities. FNIGC: Ottawa.

FNIGC (First Nations Information Governance Centre). 2014. OCAP. [Online] Available at: http://www.fnigc.ca/node/2. [Accessed 9 July 2014].

Gill, I. 2009. All That We Say Is Ours: Guujaaw and the Reawakening of the Haida Nation. Douglas \& McIntyre: Vancouver.

Habermas, J. 1984. Theory of Communicative Action / Translated by Thomas McCarthy. Beacon Press: Boston.

Habermas, J. 1989. Jürgen Habermas on Society and Politics: A Reader / Edited by Steven Seidman. Beacon Press: Boston.

Hankivsky, O. (Ed.). 2011. Health Inequities in Canada: Intersectional Frameworks and Practices. UBC Press: Vancouver.

Illich, I. 1976. Medical Nemesis: The Expropriation of Health. Pantheon Books: New York.

Irlbacher-Fox, S. 2009. Finding Dahshaa: Self-government, Social Suffering, and Aboriginal Policy in Canada. UBC Press: Vancouver.

Kalitzkus, V., and Twohig, P. (Eds.). 2009. The Tapestry of Health, Illness and Disease. Rodopi: Amsterdam.

Kemmis, S., McTaggart, R., and Nixon, R. 2014. The Action Research Planner. Springer: Singapore.

Klinenberg, E. 2003. Heat Wave: A Social Autopsy of a Disaster in Chicago. University of Chicago Press: Chicago.

Knudtson, P., and Suzuki, D. 1992. Wisdom of the Elders. Stoddart, Toronto.

Krieger, N. 2011. Epidemiology and the People's Health: Theory and Context. Oxford University Press: New York.

Lincoln, Y., and Guba, E. 1985. Naturalistic Inquiry. Sage Publications: Beverly Hills.

Meyer, L., and Avarado, B. 2010. New Worlds of Indigenous Resistance. City Lights Books: San Francisco.

Nadasdy, P. 2003. Hunters and Bureaucrats: Power, Knowledge, and Aboriginal-state Relations in the Southwest Yukon. UBC Press: Vancouver.

Neel, J. 1962. Diabetes Mellitus: A “Thrifty” Genotype Rendered Detrimental by "Progress"? American Journal of Human Genetics, 14, 353-62.

PFPIC (People's Food Policy Indigenous Circle). 2011. Resetting the table: A people's food policy for Canada. [Online] Available at: http://foodsecurecanada.org/sites/default/files/fsc-resetting20128half11-lowres-en.pdf. [Accessed 9 July 2014].

PHAC (Public Health Agency of Canada). 2014. Diabetes in Canada: Facts and Figures from a Public Health Perspective. 
[Online] Available at: http://www.phac-aspc.gc.ca/cd-mc/publica tions/diabetes-diabete/facts-figures-faits-chiffres-2011/chap6-eng.php. [Accessed 9 July 2014].

Popkin, B. 1993. Nutritional patterns and transitions. Population and Development Review, 19(1): 138-157. doi: 10.2307/2938388.

Porta, M., and Last, J. 2008. Dictionary of Epidemiology (5th Ed.). Oxford University Press: Oxford.

Reading, J. 2010. The Crisis of Chronic Disease among Aboriginal Peoples: A Challenge for Public Health, Population Health and Social Policy. University of Victoria: Victoria.

Restivo, S. (Ed.). 2005. Science, Technology, and Society: An Encyclopedia. Oxford University Press: Oxford.

Sennett, R. 2012. Together: The Rituals, Pleasures and Politics of Cooperation. Yale University Press: New Haven.
Smith, L.T. 2012. Decolonizing Methodologies (2nd Ed.). Zed Books: London and New York.

University of Victoria. 2003. Protocols and Principles for Conducting Research in an Indigenous Context. [Online] Available at: http://web.uvic.ca/igov/uploads/pdf/protocol.pdf. [Accessed 9 July 2014].

Warry, W. 2007. Ending Denial: Understanding Aboriginal Issues. Broadview Press: Peterborough.

Worthy, K. 2013. Invisible Nature: Healing the Destructive Divide between People and the Environment. Prometheus Books: New York.

Young, T., Reading, J., Elias, B., and O’Neil, J. 2000. Type 2 diabetes mellitus in Canada's first nations: Status of an epidemic in progress. Canadian Medical Association Journal, 163: 561-66. 